\title{
First application of a new portable, miniaturized system for extracorporeal membrane oxygenation
}

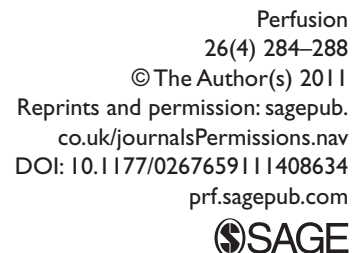

(S)AGE

\author{
T Müller', A Philipp², M Lubnow', C Weingart', \\ M Pfeifer', GAJ Riegger', C Schmid ${ }^{2}$
}

\begin{abstract}
Extracorporeal assist systems for respiratory and circulatory failure are increasingly used in intensive care medicine. Important technical innovations over the past years have resulted in improved biocompatibility and, consequently, reduced complication rates. Extracorporeal membrane oxygenation (ECMO) technology experienced a surge of use during the influenza $A(\mathrm{HINI})$ pandemic, but transport of unstable patients with life-threatening ARDS is still hazardous. We describe the first successful application of a newly developed, compact and easily portable ECMO device in a patient with severe ARDS due to influenza $A(\mathrm{HINI})$. Support with the miniaturized ECMO resulted in immediate improvement of gas exchange and a highly protective ventilation. Inspiratory pressure was decreased from 40 to $29 \mathrm{cmH}_{2} \mathrm{O}$ and tidal volume per kilogram of predicted bodyweight could be reduced from 6.5 to $3.3 \mathrm{~mL}$.

Small and efficient heart-lung assist systems will become a tool of growing importance in intensive care medicine, both for profound respiratory and cardiac failure in the future. The reduced weight and compact design of the device greatly facilitates transport and handling of unstable patients on ECMO.
\end{abstract}

\section{Keywords}

miniaturized extracorporeal membrane oxygenation, acute respiratory distress syndrome, swine flu, protective ventilation, CardioHelp

\section{Introduction}

The first successful application of extracorporeal membrane oxygenation (ECMO) for lung failure in a trauma patient was published in $1972^{1}$. Important technical innovations in recent years have led to an increasing use of extracorporeal devices to support circulatory and pulmonary function. In 2009, a randomized trial in adult patients with acute respiratory distress syndrome (ARDS) treated with ECMO indicated a significantly improved survival without disability compared to conventional ventilation support ${ }^{2}$. Transport of patients on ECMO from referring centres had not been possible in this trial. Lately, the employment of ECMO to patients with influenza A (H1N1)-associated respiratory failure showed an impressive overall survival ${ }^{3}$. Miniaturized devices for extracorporeal gas exchange showed reduced complication rates and allowed successful use of ECMO in patients with thrombocytopenia and risk of hemorrhage ${ }^{4}$.

We report on the worldwide first application in men of a new compact, portable ECMO device with integrated pump and oxygenator in a patient with severe life-threatening ARDS due to influenza A (H1N1) in May 2010.

\section{Case Report}

A 30-year-old female patient (body mass index (BMI) $\left.49.5 \mathrm{~kg} / \mathrm{m}^{2}\right)$ presented to another hospital with progressive dyspnea and elevated temperature up to $40^{\circ} \mathrm{C}$ of five days' duration. Her past history was unremarkable apart from asthma controlled with inhaled steroids. She was admitted to the intensive care unit and needed immediate intubation for worsening hypoxia. Her condition deteriorated rapidly and she was transferred to our center the same night. On admission, the patient was in need of vasopressors and invasive mechanical ventilation,

\footnotetext{
' Department of Medicine II, University Medical Center Regensburg, Regensburg, Germany

${ }^{2}$ Department of Cardiothoracic Surgery, University Medical Center Regensburg, Regensburg, Germany

Corresponding author:

Thomas Müller

Klinik und Poliklinik für Innere Medizin II

Universitätsklinikum Regensburg

Franz-Josef-Strauss Allee I I

93053 Regensburg, Germany

Email: thomas.mueller@klinik.uni-regensburg.de
} 
Table I. Gas exchange parameters and respiratory settings before, during and after extracorporeal support

\begin{tabular}{|c|c|c|c|c|c|c|c|c|c|c|c|c|c|c|}
\hline & $\begin{array}{l}\text { Pre } \\
\text { ECMO }\end{array}$ & Dayl & Day2 & Day3 & Day4 & Day5 & Day6 & Day7 & Day8 & Day9 & Day 10 & Day II & Day 12 & $\begin{array}{l}\text { Post } \\
\text { ECMO }\end{array}$ \\
\hline $\mathrm{FiO}_{2}$ & 1.0 & 0.6 & 0.60 & 0.50 & 0.50 & 0.70 & 0.50 & 0.50 & 0.40 & 0.40 & 0.40 & 0.40 & 0.35 & 0.40 \\
\hline $\begin{array}{r}\mathrm{PaO}_{2} / \mathrm{FiO}_{2} \\
(\mathrm{mmHg})\end{array}$ & 73 & 115 & 128 & 136 & 138 & 99 & 142 & 130 & 183 & 200 & 155 & 218 & 251 & 230 \\
\hline $\begin{array}{l}\mathrm{PaCO}_{2} \\
(\mathrm{mmHg})\end{array}$ & 93 & 44 & 48 & 50 & 49 & 48 & 37 & 36 & 45 & 39 & 29 & 36 & 44 & 43 \\
\hline $\mathrm{pH}$ & 7.07 & 7.39 & 7.37 & 7.38 & 7.39 & 7.40 & 7.48 & 7.49 & 7.43 & 7.45 & 7.56 & 7.47 & 7.39 & 7.35 \\
\hline $\begin{array}{l}\text { Tidal Volume } \\
\qquad(\mathrm{mL})\end{array}$ & 352 & 180 & 287 & 194 & 208 & 307 & 250 & 337 & 400 & 344 & 535 & 276 & 395 & 540 \\
\hline $\begin{array}{l}\text { TV/kg pred } \\
\text { BW (mL) }\end{array}$ & 5.9 & 3.0 & 4.8 & 3.2 & 3.5 & 5.1 & 4.2 & 5.6 & 6.7 & 5.7 & 8.9 & 4.6 & 6.6 & 9.0 \\
\hline $\begin{array}{l}\text { Minute Volume } \\
\text { (L/min) }\end{array}$ & 8.5 & 2.5 & 5.3 & 2.6 & 2.7 & 5.0 & 4.2 & 4.7 & 5.5 & 12.2 & 16.0 & 7.0 & 9.2 & 10.6 \\
\hline $\mathrm{PIP}\left(\mathrm{cmH}_{2} \mathrm{O}\right)$ & 40 & 29 & 33 & 28 & 27 & 27 & 26 & 23 & 24 & 22 & 32 & 19 & 21 & 18 \\
\hline $\operatorname{PEEP}\left(\mathrm{cmH}_{2} \mathrm{O}\right)$ & 26 & 22 & 22 & 20 & 17 & 13 & 13 & 12 & II & 10 & II & 10 & 9 & 8 \\
\hline $\begin{array}{l}\text { Norepinephrine } \\
(\mathrm{mcg} / \mathrm{kg} / \mathrm{min})\end{array}$ & 0.19 & 0.09 & 0.05 & 0.09 & 0.01 & 0.0 & 0.0 & 0.0 & 0.0 & 0.0 & 0.0 & 0.0 & 0.0 & 0.0 \\
\hline
\end{tabular}

$\left(\mathrm{FiO}_{2}=\right.$ fraction of inspired oxygen, TV = tidal volume, pred. BW = predicted bodyweight, $\mathrm{PIP}=$ positive end-inspiratory pressure, $\mathrm{PEEP}=$ positive end-expiratory pressure).

with inspiratory pressures up to $47 \mathrm{cmH}_{2} \mathrm{O}$, severe respiratory acidosis and marginal oxygenation at an $\mathrm{FiO}_{2}$ of 1.0 (Table1). Inflammatory parameters (procalcitonin $3.73 \mathrm{ng} / \mathrm{mL}$, normal $<0.1 \mathrm{ng} / \mathrm{mL}$ ) and lactic dehydrogenase (LDH $1143 \mathrm{U} / \mathrm{L}$, normal <247 U/L) were elevated; severe rhabdomyolysis was present (creatinine kinase $9721 \mathrm{U} / \mathrm{L}$, normal <167 U/L) with consequent acute renal failure. As stabilization with conventional methods was not possible, despite a trial to optimize mechanical ventilation for several hours, no improvement occurred on prone positioning or inhaled vasodilators and the chest X-ray indicated severe ARDS (Figure 1), we decided to use extracorporeal respiratory support to improve gas exchange and to avoid prolonged aggressive ventilation.

The right femoral and the right internal jugular veins were cannulated with a long 22-Fr cannula (MaquetCardiopulmonary-AG, Hirrlingen, Germany) and a short 17-Fr cannula (NovaLung-GmbH, Talheim, Germany) in the Seldinger technique. Extracorporeal membrane oxygenation was achieved with the newly developed Cardiohelp (Maquet-Cardiopulmonary-AG, Hirrlingen, Germany), which has been used for the first time (Figure 2, during transport to the computerized tomography (CT) scan). This device has a gas exchange surface area of $1.8 \mathrm{~m}^{2}$, a heat exchange surface area of $0.4 \mathrm{~m}^{2}$ and a priming volume of about $600 \mathrm{~mL}$. The diffusion membrane of the oxygenator is made of polymethylpentene and the system is heparin coated (Bioline Coating ${ }^{\mathrm{TM}}$ ) from tip to tip. After initiation of the extracorporeal support, invasiveness of mechanical ventilation could be decreased immediately; respiratory parameters before, during and after ECMO are presented in Table 1. The polymerase chain reaction (PCR) for Influenza A-H1N1-RNA ${ }^{5}$ proved to be positive in the bronchiolo-alveolar lavage (BAL) the same day $\left(10^{7}\right.$ copies) and therapy with oseltamivir $150 \mathrm{mg}$ tid was started. After 10 days, the PCR-test was still positive ( $10^{4}$ copies), but after 17 days it proved to be negative in the BAL.

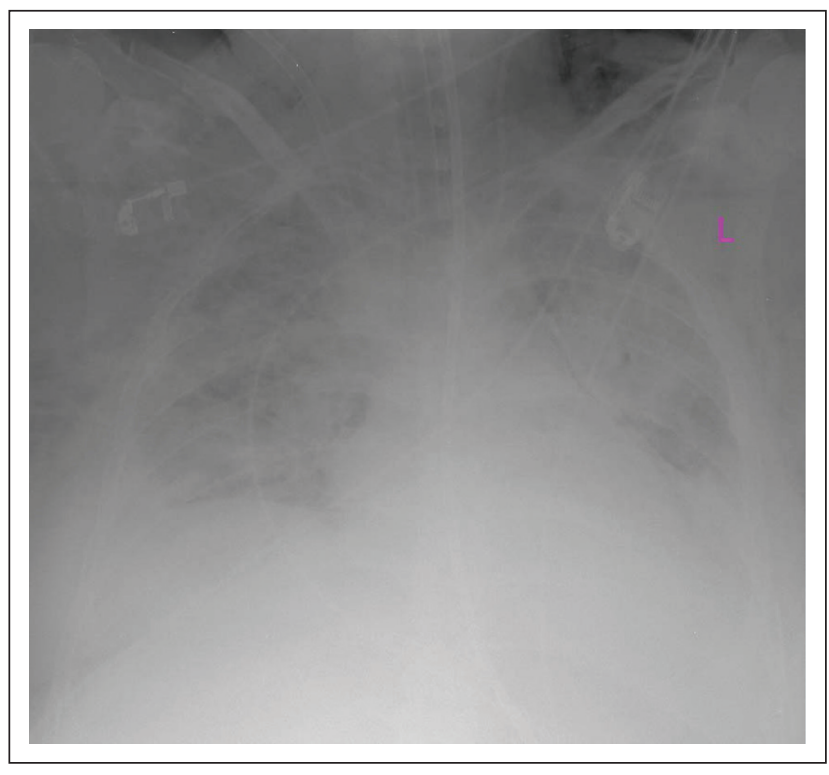

Figure I. Chest X-ray after implementation of ECMO; backflow cannula in right internal jugular vein. 


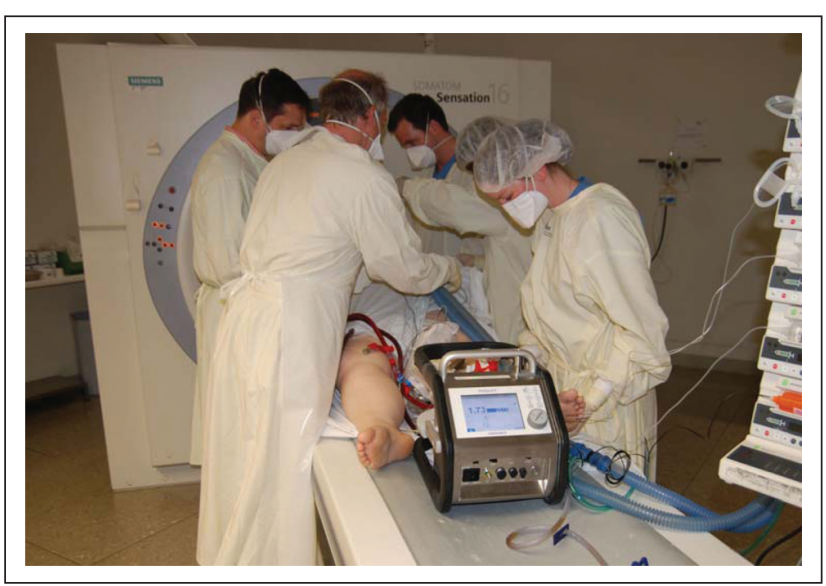

Figure 2. Patient on transport with portable miniaturized ECMO.

Further clinical course was complicated by a hemorrhage into the right thigh due to difficult cannulation, which was controlled conservatively with reduced heparin dosing and an intended activated partial thromboplastin time (aPTT) of 40-45 seconds. The maximum decrease of platelets from initial values was less than $20 \%$ during ECMO therapy (Table 2). After early tracheotomy, sedation was tapered and the patient was supported with neurally adjusted ventilatory assist (NAVA) in a highly protective mode. Due to reduced anticoagulation, the oxygenator had to be exchanged once after 1 week of therapy. This was accomplished in less than one minute, without deterioration of the patient during the exchange, as $\mathrm{FiO}_{2}$ was temporarily increased. Weaning from ECMO support was possible on the 12th day of ECMO treatment after first slowly reducing blood flow to $1.5 \mathrm{~L} / \mathrm{min}$ and sweep gas flow to $1 \mathrm{~L} / \mathrm{min}$. Thereafter, sweep gas flow was paused for 1 hour and ECMO was removed, as the patient remained stable. Renal function returned after two weeks and the patient was discharged from the ICU after 21 days, with uneventful further recovery.

\section{Discussion}

Extracorporeal membrane oxygenation is becoming increasingly recognized as a potentially life-saving technique to secure vital gas transfer in life-threatening respiratory failure. During the Influenza A-(H1N1) pandemic, intensivists throughout the world used ECMO for the most severe cases of viral pneumonia. ECMO not only secures gas transfer, but also allows highly protective ventilation. It can be assumed that, thereby, the magnitude of ventilator-induced lung injury will be reduced and time is gained for the diseased lung to heal.

Historic ECMO trials could not demonstrate a significant reduction of mortality in adults ${ }^{6,7}$. This was mainly caused by the need for a pronounced systemic anticoagulation due to the large foreign surface of early devices, which resulted in severe bleeding complications. In contrast, modern devices are characterized by a largely improved biocompatibility, with reduced artificial surfaces, heparin coating, plasma-resistant gas exchange membranes and centrifugal pumps. The new Cardiohelp heart-lung assist system integrates all components of ECMO into one compact device which is portable with a weight of less than $13 \mathrm{~kg}$. Therefore, intra-hospital (Figure 2) and inter-hospital transport is greatly facilitated. Transfer of patients to specialized centers with ECMO support, who would otherwise be too unstable for transport, is becoming increasingly important ${ }^{8}$.

Table 2. ECMO settings, efficiency of gas transfer, and ECMO-related laboratory parameters before, during and after extracorporeal support

\begin{tabular}{|c|c|c|c|c|c|c|c|c|c|c|c|c|c|c|}
\hline & $\begin{array}{l}\text { Pre } \\
\text { ECMO }\end{array}$ & Dayl & Day2 & Day3 & Day4 & Day5 & Day6 & Day7 & Day8 & Day9 & Day 10 & Dayl I & Day 12 & $\begin{array}{l}\text { Post } \\
\text { ECMO }\end{array}$ \\
\hline $\begin{array}{l}\text { Blood Flow } \\
\text { (L/min) }\end{array}$ & & 2.0 & 2.0 & 2.7 & 2.5 & 2.6 & 2.4 & 2.2 & 2.0 & 1.9 & 1.9 & 1.8 & 1.5 & \\
\hline $\begin{array}{l}\text { Sweep Gas } \\
\text { Flow (L/min) }\end{array}$ & & 5 & 5 & 7 & 10 & 12 & 6 & 9 & 5 & 5 & 5 & 6 & I & \\
\hline rpm & & 1850 & 1855 & 2300 & 2300 & 2300 & 2300 & 2135 & 2135 & 2135 & 2136 & 1990 & 2015 & \\
\hline $\begin{array}{l}\mathrm{O}_{2} \text { Transfer } \\
(\mathrm{mL} / \mathrm{min})\end{array}$ & & 130 & 114 & 148 & 122 & 117 & 139 & 114 & 90 & 116 & 114 & 85 & 67 & \\
\hline $\begin{array}{c}\mathrm{CO}_{2} \text { Transfer } \\
(\mathrm{mL} / \mathrm{min})\end{array}$ & & 244 & 210 & 170 & 225 & 237 & 168 & 202 & 164 & 160 & 114 & $13 \mid$ & 40 & \\
\hline Platelets (/nl) & 205 & 209 & 220 & 182 & 158 & 162 & 176 & 224 & 274 & 288 & 320 & 246 & 200 & 182 \\
\hline Free $\mathrm{Hb}(\mathrm{mg} / \mathrm{L})$ & 98 & & & & & 57 & & 50 & 91 & 254 & 61 & 104 & 56 & \\
\hline aPTT & 39 & 60 & 42 & 43 & 44 & 50 & 47 & 55 & 43 & 36 & 38 & 29 & 30 & 31 \\
\hline
\end{tabular}

(rpm $=$ revolutions per minute, Free $\mathrm{Hb}=$ free hemoglobin (normal $<20 \mathrm{mg} / \mathrm{L})$, aPTT $=$ activated partial thromboplastin time) 
Table 3. Laboratory parameters before, during and after extracorporeal support

\begin{tabular}{lllllllllllllll}
\hline & $\begin{array}{l}\text { Pre } \\
\text { ECMO }\end{array}$ & Dayl & Day2 & Day3 & Day4 & Day5 & Day6 & Day7 & Day8 & Day9 & Dayl0 & Dayll & Dayl2 & $\begin{array}{l}\text { Post } \\
\text { ECMO }\end{array}$ \\
\hline CK (U/L) & 9721 & 3134 & 1380 & 739 & 405 & 275 & 394 & 1003 & 1184 & 960 & 2505 & 3218 & 2590 & 1334 \\
LDH (U/L) & 1143 & 1014 & 870 & 797 & 797 & 773 & 803 & 679 & 572 & 556 & 517 & 421 & 415 & 416 \\
AST (U/L) & 172 & 150 & 107 & 75 & 59 & 62 & 95 & 121 & 98 & 87 & 97 & 145 & 130 & 90 \\
ALT (U/L) & 66 & & & 41 & & & 82 & & & & 128 & & & 85 \\
Crea (mg/dL) & 2.6 & 3.8 & 3.1 & 3.3 & 2.5 & 2.2 & 2.2 & 1.9 & 3.0 & 2.5 & 2,3 & 3.3 & 3.1 & 3.3 \\
\hline
\end{tabular}

$(\mathrm{CK}=$ creatinine kinase, $\mathrm{LDH}=$ lactic dehydrogenase, $\mathrm{AST}=$ aspartatetransferase, $\mathrm{ALT}=$ alaninetransferase, $\mathrm{Crea}=$ creatinine $)$

With the new device, saturation of inflowing central venous blood, hemoglobin and hematocrit are recorded continuously. Thus, central venous saturation presents information about swings in oxygen consumption in the course of the disease. The online documentation of inflow pressure values, recorded with stop-cock-free pressure chips, is helpful with respect to the need of volume substitution to increase venous filling. Transmembrane pressures, acquired automatically, can be useful to guide the necessity of an oxygenator-exchange.

Small and efficient heart-lung assist systems will probably become a tool of growing importance in intensive care medicine in the future. Not only will they be applied in severe hypoxemic and/or hypercapnic respiratory failure to decrease aggressiveness of invasive ventilation, but will also be used more often in circulatory failure. For cardiogenic shock and circulatory arrest unresponsive to conventional therapy, veno-arterial ECMO has been used successfully,10. Pesenti and colleagues recently have been looking forward to further improvements in extracorporeal gas exchange technology, which had undergone huge progress in the last 30 years ${ }^{11}$. We believe this new device, whose first clinical application in the world has been described here, will pave the way for new developments.

\section{Conflict of interest}

Thomas Müller has received lecture honoraria from Maquet CardioPulmonary Care, Germany.

Alois Philipp is Chief Perfusionist at the University Medical Center Regensburg and a member of the technical advisory board of Maquet Cardiopulmonary Care.

All other authors have no conflict of interest to declare.

\section{Author Acknowledgments}

Thomas Müller, Matthias Lubnow, Christian Weingart, Michael Pfeifer, and Günter AJ Riegger were actively involved in the treatment of the patient. Alois Philipp and Christof Schmid were responsible for implementation and supervision of the new ECMO device. All authors made substantial contributions to the manuscript and critically revised the final version of the report.

\section{Funding}

This research received no specific grant from any funding agency in the public, commercial, or not for-profit sectors.

\section{References}

1. Hill JD, O’Brien TG, Murray JJ, et al. Prolonged extracorporeal oxygenation for acute post-traumatic respiratory failure (shock-lung syndrome). Use of the Bramson membrane lung. N Engl J Med 1972; 286: 629-634.

2. Peek GJ, Mugford M, Tiruvoipati R, et al. for the CESAR trial collaboration. Efficacy and economic assessment of conventional ventilatory support versus extracorporeal membrane oxygenation for severe adult respiratory failure (CESAR): a multicentre randomised controlled trial. The Lancet 2009; 374: 1351-1363.

3. Australia and New Zealand Extracorporeal Membrane Oxygenation (ANZ ECMO) Influenza Investigators, Davies A, Jones D, Bailey M, et al. Extracorporeal membrane oxygenation for 2009 influenza A (H1N1) acute respiratory distress syndrome. JAMA 2009; 302: 1888-1895

4. Müller T, Philipp A, Luchner A, et al. A new miniaturized system for extracorporeal membrane oxygenation in adult respiratory failure. Crit Care 2009; 13: R205

5. Panning M, Eickmann M, Landt O, et al. Detection of influenza $\mathrm{A}(\mathrm{H} 1 \mathrm{~N} 1) \mathrm{v}$ virus by real-time RT-PCR. Euro Surveill. 2009 Sep 10; 14(36). pii: 19329.

6. Zapol WM, Snider MT, Hill JD, et al. Extracorporeal membrane oxygenation in severe respiratory failure. A randomised prospective study. JAMA 1979; 242: 2193-2196.

7. Morris AH, Fallace CJ, Menlove RL, et al. Randomized clinical trial of pressure-controlled inverse ratio ventilation and extracorporeal $\mathrm{CO}_{2}$ removal for adult respiratory distress syndrome. Am J Respir Crit Care Med 1994; 149: 295-305. 
8. Arlt M, Philipp A, Zimmermann M, et al. Emergency use of extracorporeal membrane oxygenation in cardiopulmonary failure. Artif Organs 2009; 33: 696-703

9. Combes A, Leprince P, Luyt CE, et al. Outcomes and longterm quality-of-life of patients supported by extracorporeal membrane oxygenation for refractory cardiogenic shock. Crit Care Med 2008; 36: 1404-1411
10. Chen YS, Lin JW, Yu HY, et al. Cardiopulmonary resuscitation with assisted extracorporeal life-support versus conventional cardiopulmonary resuscitation in adults with in-hospital cardiac arrest: an observational study and propensity analysis. Lancet 2008; 372: 554-561

11. Pesenti A, Zanella A, Patroniti N. Extracorporeal gas exchange. Curr Opin Crit Care 2009; 15: 52-58 